УДК 547.972

\title{
ИЗУЧЕНИЕ НАДЗЕМНОЙ ЧАСТИ GLYCYRRHIZA GLABRA В КАЧЕСТВЕ ПЕРСПЕКТИВНОГО СЫРЬЯ ДЛЯ ПРОИЗВОДСТВА ПРЕПАРАТОВ НА ОСНОВЕ ФЛАВОНОИДОВ
}

\author{
(C) М.А. Маматханова, Б.А. Абдурахманов *, Б.А. Нигматуллаев, Г.Б. Сотимов, Р.М. Халилов, \\ А.У. Маматханов \\ Институт химии растительных веществ им. акад. С.Ю. Юнусова АН РУз, \\ ул. Мирзо-Улугбека, 77, Ташкент, 100170 (Узбекистан), \\ e-mail:plant_inst@icps.org.uz; bahti86.86@mail.ru
}

На основе суммы флавоноидов надземной части солодки голой разработан препарат Глацембрин противовоспалительного действия.

Оценку качества надземной части солодки голой (Glycyrrhiza glabra) предложено проводить по содержанию суммы флавоноидов. При проведении качественной реакции извлечения из сырья с раствором хлорида окисного железа появлялось коричневато-зеленое окрашивание, которое свидетельствует о наличии соединений фенольной природы. Разработана спектрофотометрическая методика количественного определения суммы флавоноидов в пересчете на пиноцембрин. Установлено, что содержание флавоноидов в сырье составило не менее 1,0\%. Определено содержание флавоноидов в надземной части солодки в зависимости от почвенно-климатических условий, а также по периодам вегетации, показано, что заготовку сырья следует производить в период массового цветения (вторая половина мая). Относительная ошибка предложенной методики $-6,47 \%$. Изучены изменение содержания суммы флавоноидов по истечении времени в надземной части солодки голой и установлено, что сырье стабильно хранится в течение двух лет. Определены массивы зарослей солодки в Узбекистане. Установлено, что наибольшая площадь промысловых массивов зарослей солодки находится в Республике Каракалпакстан и составляет более 15000 га.

Ключевые слова: солодка голая, надземная часть, Glycyrrhiza glabra, сырье, сумма флавоноидов, препарат противовоспалительного действия, глацембрин, пиноцембрин, спектрофотометрический метод, Республика Каракалпакстан.

Работа выполнена в рамках проекта ГНТП № ФА-А11-T195 (2012-2014).

Маматханова Мунирахон Ахматхановна - кандидат технических наук, младший научный сотрудник экспериментально-технологической лаборатории, e-mail:munir_05@mail.ru

Абдурахманов Бахтияр Алимович - младший научный сотрудник экспериментально-технологической лаборатории, e-mail: bahti86.86@mail.ru

Нигматуллаев Бахтияр Алимович - младший научный сотрудник лаборатории лекарственных и технических растений

Сотимов Гайрат Бахтиёривич - кандидат технических наук, старший научный сотрудник экспериментальнотехнологической лаборатории

Халилов Равшанжон Муратджанович - кандидат технических наук, старший научный сотрудник экспериментально-технологической лаборатории, e-mail: dr.khalilov@rambler.ru

Маматханов Ахмадхон Умарханович - доктор технических наук, ведущий научный сотрудник экспериментально-технологической лаборатории, e-mail:munir_05@mail.ru

\section{Введение}

Растение солодка голая (солодка гладкая, лакричник) (Glycyrrhiza glabra, сем. Fabaceae) многолетнее корневищное травянистое растение высотой до 150, реже до 200 см.

Солодка голая относится к средиземноморскому виду. В Узбекистане данное растение произрастает в поймах рек Амударьи, Сырдарьи и Зарафшана, на берегах их притоков. Поднимаясь до среднего пояса гор до высоты 2000 м над уровнем моря, солодка местами образует почти чистые солодковые заросли [1].

Из корней и корневищ солодки выделены: сапонин - глицирризин (23\%), придающий сладкий вкус корням, флавоноиды, глабровая кислота, стероиды, эфирное масло, аспарагин, аскорбиновая кислота, горечи, пигменты и др. [2].

\footnotetext{
* Автор, с которым следует вести переписку.
} 
Солодковое сырье (корни) экспортируется в ряд развитых стран мира, таких как США, Великобритания, Германия, Япония, Корея и др. [3]. При промышленной заготовке корней надземная часть солодки выбрасывается. Но, как известно, надземные части солодки содержат биологически активные соединения, такие как полисахариды, дубильные вещества, флавоноиды, тритерпеноиды, витамины и др. [4].

Флавоноидный состав травы солодки голой представлен пиноцембрином, глабранином, пурнетином, кверцетином, кемпферолом, астрагалином, глифазидом и др. [5]. На основе суммы флавоноидов надземной части солодки голой в Институте химии растительных веществ АН РУз им. акад. С.Ю. Юнусова (ИХРВ АН РУз) (Республика Узбекистан, город Ташкент) разработана технология получения субстанции Глацембрин и его лекарственной формы в виде таблеток.

Фармакологические исследования Глацембрина показали, что препарат обладает противовоспалительным действием [6]. Это открывает перспективы использования в фармацевтической промышленности надземной части солодки голой в качестве сырья для создания стандартизованных препаратов, проявляющих противовоспалительную и другие виды активности.

По литературным данным известно, что флавоноиды, выделенные из надземной части солодки голой, обладают выраженным противовоспалительным действием [7-10]. Исходя из этого мы предлагаем вести стандартизацию сырья солодки по содержанию суммы флавоноидов.

Цель настоящей работы - разработка методики качественного и количественного анализа флавоноидов в надземной части Glycyrrhiza glabra, произрастающей на территории Республики Узбекистан.

\section{Экспериментальная часть}

В качестве сырья надземной части солодки собирали как цветущие, так и вегетативные побеги растения в фазе цветения с мая по июль в зависимости от района произрастания. Методику разрабатывали на образцах сырья, собранного в Республике Каракалпакстан, где сосредоточены основные запасы солодки. Надземные части срезали серпом на высоте 3-5 см от поверхности почвы или проводили сбор механизированным способом. Срезанную массу измельчали на кусочки размером 2-6 см, сушили на открытом воздухе в тени.

Перед сбором производящее растение было идентифицировано путем сопоставления с гербарными образцами Центрального гербария Узбекистана (TASH) при Институте генофонда растительного и животного мира АН РУз.

Образцы сырья хранятся на приспособленном для хранения растительного сырья складе ИХРВ АН РУз.

Готовое сырье представляет собой смесь кусочков стеблей, черешков листовых пластинок и цветков. Цвет сырья - пепельно-зеленый.

В готовом сырье отсутствуют части других растений, одревесневшие, загнившие (побуревшие, пораженные вредителями части), органическая примесь (части других неядовитых растений), минеральная примесь (земля, песок, камешки).

Числовые показателя сырья изучали по общепринятым методикам $[11,12]$.

Выделение суммы флавоноидов проводили по следующей методике: Аналитическую пробу сырья измельчали до размера частиц, проходящих сквозь сито с отверстиями диаметром 2 мм. Около 1,0 г (точная навеска) измельченного сырья помещали в коническую колбу вместимостью 250 мл, заливали 60 мл $96 \%$ этилового спирта, присоединяли к обратному холодильнику и нагревали на кипящей водяной бане в течение 30 мин. Затем колбу охлаждали до комнатной температуры и извлечение фильтровали через бумажный фильтр в мерную колбу вместимостью 250 мл. Экстракцию повторяли вышеуказанным способом еще дважды. Извлечения фильтровали в ту же мерную колбу, промывали фильтр 96\% этиловым спиртом, доводили объем фильтрата тем же спиртом до метки и перемешивали раствор. 5 мл полученного раствора переносили в мерную колбу вместимостью 25 мл, доводили тем же спиртом до метки и перемешивали. Полученное извлечение использовали для качественных реакций и количественного определения.

Качественные реакции. 1. Для качественного определения флавоноидов в сырье солодки использовали реакцию на фенольный гидроксил, для этого в пробирку с 1 мл извлечения добавляли 4 мл 95\% этилового спирта и 3-4 капли 30\% раствора хлорида окисного железа, наблюдали изменения окраски раствора.

2. На хроматографическую пластинку «Силуфол» УФ-254 (10×15) наносили 0,05 мл извлечения, рядом по 0,05 мл (100 мкг) растворов свидетелей пиноцембрина, глабранина и прунетина. Стандартные образцы флавоноидов пиноцембрина, глабранина и прунетина ранее были выделены и идентифицированы 
в лаборатории химии кумаринов и терпеноидов ИХРВ АН РУз. Пластинку с нанесенными пробами высушивали на воздухе в течение 1 ч и хроматографировали восходящим способом в камере, предварительно насыщенной смесью растворителей хлороформ - метанол - бензол (19:1:1) Когда фронт растворителей прошел 7 см, пластинку вынимали из камеры, сушили на воздухе 10-15 мин и просматривали в УФ-свете $(\lambda=254$ нм). На уровне пятна свидетеля наблюдали пятна пиноцембрина, глабранина и прунетина.

Количественное определение содержания суммы флавоноидов. Согласно литературным данным установлено, что содержание пиноцембрина в надземной части солодки достигает $0,9 \%$. Учитывая, что противовоспалительная активность пиноцембрина превышает противовоспалительную активность других флавоноидов солодки [6], количественное определение суммы флавоноидов осуществляли в пересчете на пиноцембрин.

Оптическую плотность аналитической пробы измеряли на спектрофотометре при длине волны 292 нм. Параллельно измеряли оптическую плотность раствора стандартного образца пиноцембрина.

Содержание суммы флавоноидов в сырье в процентах $(X)$ рассчитывали по формуле

$$
X=\frac{a_{0} \times D \times 1 \times 250 \times 25 \times 100 \times 100}{D_{0} \times a \times 100 \times 25 \times 5 \times(100-W)}
$$

где $D$ - оптическая плотность раствора анализируемого сырья; $D_{0}$ - оптическая плотность раствора СО пиноцембрина; $a$ - навеска сырья, в граммах; $a_{0}$ - навеска пиноцембрина, в граммах; $W$ - потеря в массе при высушивании сырья, в процентах.

Примечание. Приготовление раствора стандартного образца (CO) пиноцембрина. Около 0,05 г СО пиноцембрина (точная навеска) помещали в мерную колбу вместимостью 100 мл, добавляли до метки 96\% этиловый спирта и перемешивали. 1 мл полученного раствора переносили в мерную колбу вместимостью 25 мл, доводили объем раствора до метки 96\% этиловым спиртом и перемешивали. Раствор использовали свежеприготовленным.

Расчет метрологической характеристики метода анализа проведен по методу, приведенному в Государственной фармакопее издания XI [11].

\section{Обсуждение результатов}

При проведении качественной реакции извлечения из сырья с раствором хлорида окисного железа появлялось коричневато-зеленое окрашивание, которое свидетельствует о наличии соединений фенольной природы.

Методом хроматографии в тонком слое сорбента было установлено наличие в исследуемом извлечения пятен с величиной $\mathrm{R}_{\mathrm{f}} 0,42 ; \mathrm{R}_{\mathrm{f}} 0,45 ; \mathrm{R}_{\mathrm{f}} 0,18$, которые совпадали со значениями $\mathrm{R}_{\mathrm{f}}$ стандартных образцов пиноцембрина, глабранина и пурнитина соответственно.

Метрологические характеристики методики количественного определения суммы флавоноидов в траве солодки при $\mathrm{n}=6$ и $\mathrm{P}=95 \%$ приведены в таблицах 1 и 2.

Относительная ошибка результата отдельного определения составляет $\pm 6,47 \%$. Таким образом, разработанная методика качественного и количественного определения суммы флавоноидов может быть использована для оценки качества травы солодки.

Для промышленного производства лекарственных препаратов на основе надземной части солодки целесообразно использовать сырье с содержанием суммы флавоноидов в пересчете на пиноцембрин не менее $1,0 \%$.

Разработанная методика была апробирована на 5 образцах надземной части солодки. Стабильность сырья в процессе хранения в естественных условиях установлена на основании результатов анализа 5 проб сырья, заготовленного в мае 2012 г. (табл. 3).

Как видно из таблицы 3, содержание суммы флавоноидов в заготовленном сырье колеблется от 1,37 до 1,57\%. При этом сырье стабильно хранится в течение двух лет.

Таблица 1. Результаты единичных измерений количества флавоноидов в надземной части солодки

\begin{tabular}{c|c|c|c|c|c|c|c}
\hline $\mathrm{I}$ & $\mathrm{X}_{\mathrm{cp}}$ & 1 & 2 & 3 & 4 & 5 & 6 \\
\hline $\mathrm{X}$ & 1,515 & 1,480 & 1,510 & 1,540 & 1,570 & 1,530 & 1,460 \\
\hline
\end{tabular}

Таблица 2. Метрологические характеристики метода

\begin{tabular}{c|c|c|c|c|c|c|c}
\hline $\mathrm{F}$ & $\mathrm{S}^{2}$ & $\mathrm{~S}$ & $\mathrm{P}, \%$ & $\mathrm{t}(\mathrm{p}, \mathrm{f})$ & $\pm \Delta \mathrm{x}$ & $\pm \varepsilon, \%$ & $\pm \varepsilon_{\text {cp }} \%$ \\
\hline 5 & 0,001565 & 0,03956 & 95 & 2,57 & 0,1016692 & 6,47 & 2,73 \\
\hline
\end{tabular}


Определение количества флавоноидов в надземной части растения по периодам вегетации из различных мест произрастания позволяет определить оптимальные сроки и место сбора сырья. Изменение содержания флавоноидов в траве солодки в зависимости от места произрастания, а также динамика накопления их по периодам вегетации не были изучены. В связи с этим нами в 2011-2012 гг. были организованы экспедиции в различные регионы Республики Узбекистан по сбору образцов надземной части солодки в различные периоды вегетации.

Результаты анализа собранных образцов приведены в таблице 4.

Из данных таблицы 4 видно, что содержание флавоноидов в надземной части солодки голой колеблется от 1,18 до $3,26 \%$. Это объясняется уровнем засоленности почвы районов произрастания солодки, а именно: чем больше засоленность почвы, тем выше содержание флавоноидов (2,33-3,26 \%).

Образцы сырья №1-5 заготовлены из районов с большим засолением почвы, а №6-11 - с меньшим засолением (в орошаемых районах). Известно, что почва территорий Республики Каракалпакстан, Бухарской, Хорезмской, Джизакской областей является сильно засоленной, тогда как почва Ташкентской, Сурхандарьинской, Кашкадарьинской областей и Ферганской долины является слабозасоленной вследствие орошаемого земледелия.

Полученные результаты (табл. 4) также показали, что наибольшее содержание флавоноидов в надземной части солодки наблюдается в период массового цветения (вторая половина мая), следовательно, заготовку сырья нужно производить в этот период.

По результатам экспедиции также были определены массивы зарослей солодки на территории Узбекистана. Установлено, что наибольшая площадь промысловых массивов зарослей солодки находится в Республике Каракалпакстан и составляет более 15000 га.

Таблица 3. Результаты исследования стабильности надземной части Glycyrrhiza glabra по содержанию суммы флавоноидов, \%

\begin{tabular}{|c|c|c|c|c|c|c|}
\hline \multicolumn{7}{|c|}{ Срок хранения } \\
\hline $\begin{array}{c}\text { Свежесобран- } \\
\text { ное сырье }\end{array}$ & 1 год & $\begin{array}{l}1 \text { год } \\
6 \text { мес. }\end{array}$ & 2 года & $\begin{array}{l}2 \text { года } \\
6 \text { мес. }\end{array}$ & 3 года & $\begin{array}{l}3 \text { года } \\
6 \text { мес. }\end{array}$ \\
\hline \multicolumn{7}{|c|}{ Серия №1 } \\
\hline 1,51 & 1,51 & 1,51 & 1,51 & 1,49 & 1,44 & 1,41 \\
\hline \multicolumn{7}{|c|}{ Серия №2 } \\
\hline 1,44 & 1,44 & 1,44 & 1,44 & 1,42 & 1,40 & 1,37 \\
\hline \multicolumn{7}{|c|}{ Серия №3 } \\
\hline 1,49 & 1,49 & 1,49 & 1,49 & 1,46 & 1,43 & 1,41 \\
\hline \multicolumn{7}{|c|}{ Серия №4 } \\
\hline 1,57 & 1,57 & 1,57 & 1,57 & 1,54 & 1,50 & 1,47 \\
\hline \multicolumn{7}{|c|}{ Серия №5 } \\
\hline 1,55 & 1,55 & 1,55 & 1,55 & 1,49 & 1,45 & 1,41 \\
\hline
\end{tabular}

Таблица 4. Динамика накопления флавоноидов в надземной части Glycyrrhiza glabra в зависимости от места произрастания и периода вегетации

\begin{tabular}{c|l|c|c|c}
\hline $\begin{array}{c}\text { № } \\
\text { образца }\end{array}$ & \multicolumn{1}{|c|}{ Место сбора } & $\begin{array}{c}\text { Дата } \\
\text { сбора }\end{array}$ & Период развития & $\begin{array}{c}\text { Содержание } \\
\text { флавоноидов, \% }\end{array}$ \\
\hline 1 & Каракалпакстан (Турткульский район) & 5 мая & Начало цветения & 2,33 \\
2 & Хорезмская область (окрестности Ургенча) & 10 мая & Начало цветения & 2,67 \\
3 & Хазораспский район & 15 мая & Массовое цветение & 3,07 \\
4 & Бухарская область (окрестности Вобкента) & 10 мая & Начало цветения & 2,38 \\
5 & Джизахская область (окрестности Пахтакора) & 20 мая & Массовое цветение & 3,26 \\
6 & Ташкентская область & 10 июня & Плодоношение & 1,18 \\
& (Фермерское хозяйство «Иттифок») & 20 июня & Плодоношение & 1,30 \\
7 & Зангиатинский район & 10 июня & Плодоношение & 1,25 \\
9 & Сурхандарьинская область (Сариасийский район) & 20 мая & Массовое цветение & 1,42 \\
10 & Кашкадарьинская область (вдоль трассы Яккабаг - & & 1,30 \\
11 & Шахрисабз) & 21 июня & Плодоношение & 1,51 \\
\hline
\end{tabular}




\section{Выводы}

1. Изучены условия спектрофотометрического определения суммы флавоноидов из надземной части солодки голой.

2. На основании приведенных фактических данных и, учитывая ошибку спектрофотометрического определения $\pm 6,47 \%$, регламентируем содержание суммы флавоноидов в надземной части Glycyrrhiza glabra не менее $1,0 \%$ в пересчете на пиноцембрин.

3. Установлена зависимость содержания флавоноидов в надземной части Glycyrrhiza glabra от периода вегетации растения и места произрастания. Показано, что заготовку сырья следует производить во второй половине мая - в период массового цветения производящего растения. Срок хранения сырья составляет 2 года.

4. Определены массивы зарослей солодки в Республике Узбекистан. Установлена наибольшая площадь промысловых массивов зарослей солодки, находящаяся в Республике Каракалпакстан и составляющая более 15000 га.

\section{Список литературы}

1. Короткова Е.Е. Род 513. Glycyrrhiza L. - Солодка. Мия // Флора Узбекистана. Ташкент, 1978. 825 с.

2. Растительные ресурсы СССР. Цветковые растения, их химический состав, использование. Семейства Hydrangeaceae-Haloragaceae. Л., 1987. Т. 3. 328 c.

3. Шамсутдинов 3.Ш. Галофитное растениеводство: концепция, опыт, проблемы // Новые нетрадиционные растения и перспективы их использования: материалы Четвертого Международного симпозиума. М., 2001. С. $387-389$.

4. Юлдашев М.П., Ботиров Э.Х., Вдовин А.Д., Абдуллаев А.Д. Глабризофлавон - новый изофлавон из Glycyrrhiza glabra L. // Биоорганическая химия. 2000. Т. 26. №11. С. 873-876.

5. Ботиров Э.Х., Киямитдинова Ф., Маликов В.М. Флавоноиды надземной части Glycyrrhiza glabra // Химия природных соединений. 1986. №1. С. 111-112.

6. Вахабов А.А., Хасанова Р.Х., Набиев А.Н., Юлдашев М.П. К исследованию фармакологии глацембрина // Фармацевтический вестник Узбекистана. 2010. №2. С. 43-46.

7. Вахабов А.А., Аминов С.Д., Хасанова Р.Х. О противовоспалительной активности пиноцембрина // Доклады Академии наук РУз. 1993. №10. С. 43-45.

8. Аминов С.Д., Вахабов А.А., Хасанова Р.Х. О противовоспалительной активности флавоноидов, выделенных из надземной части растения солодка и ее производных // Доклады Академии наук РУз. 1995. №9/10. С. $43-45$.

9. Хасанова Р.Х., Вахабов А.А., Аминов С.Д. О фармакологических свойствах пиноцембрина // Создание лекарственных ресурсов лечебно-профилактические средства и их использование в медицинской практике: материалы 1 Республиканской научно-производственной конференции. Самарканд, 1996. С. 101-102.

10. Хасанова Р.Х., Набиев А.Н., Вахабов А.А. Пинацембрин - препарат из солодки голой // Гастроэнтерология Санкт-Петербурга. 2003. №2-3. С. 180.

11. Государственная фармакопея: ХІ издание. Вып. 1. М., 1987. 336 с.

12. Государственная фармакопея: ХІ издание. Вып. 2. М., 1990. 400 с.

Поступило в редакиию 15 апреля 2015 г.

После переработки 1 февраля 2016 г. 
Mamatkhanova M.A., Abdurakhmanov B.A. *, Nigmatullaev B.A., Sotimov G.B., Khalilov R.M., Manatkhanov A.U. STUDY OF AERIAL PARTS OF GLYCYRRHIZA GLABRA AS PROMISING RAW MATERIALS FOR THE PRODUCTION OF DRUGS

Acad. S.Yu. Yunusov Institute of the Chemistry of Plant substances, Uzbekistan Academy of Sciences, ul. M. Ulugbeka,

77,Tashkent,100170(Uzbekistan),e-mail:plant_inst@icps.org.uz; bahti86.86@mail.ru

New anti-inflammatory preparation «Glatsembrin» was developed on the basis of the sum of flavonoids of the aerial part of licorice (Glycyrrhiza glabra). Assessment of the quality of the aerial part of licorice had been to make by the content of total flavonoids. During the qualitative reaction of the extraction from raw materials with a solution of ferric chloride brownishgreen colour was appeared, which indicates the presence of compounds of phenolic nature. A spectrophotometric method for quantitative determination of total flavonoids converting to pinocembrin was developed. The content of flavonoids in the raw material was not less than $1,0 \%$. The content of flavonoids in the aerial part of licorice at various vegetation periods collected from different places of growth was identified. Our data suggest that the raw material should be collected during the period of mass flowering (in the second half of May). Relative error of the proposed method is $6,47 \%$. The changes of the content of total flavonoids after time in the aerial part of licorice were studied and it was found that the raw material is kept stable for two years. Arrays thickets of licorice in Uzbekistan were defined. It was founded that the largest area of commercial arrays of licorice more than 15,000 hectares locates in the Republic of Karakalpakstan.

Keywords: licorice, aerial part, Glycyrrhiza glabra, raw material, flavonoids, anti-inflammatory preparation, «Glatsembrin», pinocembrin, spectrophotometric method, The Republic of Karakalpakstan.

\section{References}

1. Korotkova E.E. Rod 513. Glycyrrhiza L. - Solodka. Mija. Flora Uzbekistana. [Rhode 513. Glycyrrhiza L. - Licorice. Mriya. Flora of Uzbekistan]. Tashkent, 1978, 825 p. (in Russ.).

2. Rastitel'nye resursy SSSR. Cvetkovye rastenija, ih himicheskij sostav, ispol'zovanie. Semejstva HydrangeaceaeHaloragaceae. [Plant resources of the USSR. Flowering plants, their chemical composition, the use. Family Hydrangeaceae-Haloragaceae]. Leningrad, 1987, vol. 3, 328 p. (in Russ.).

3. Shamsutdinov Z.Sh. Novye netradicionnye ras-tenija $i$ perspektivy ih ispol'zovanija: materialy chetvertogo mezhdunarodnogo simpoziuma. [New unconventional plants and prospects of their use: Proceedings of the fourth international symposium]. Moscow, 2001, pp. 387-389. (in Russ.).

4. Juldashev M.P., Botirov Je.H., Vdovin A.D., Abdullaev A.D. Bioorganicheskaja himija, 2000, vol. 26, no. 11, pp. 873-876. (in Russ.).

5. Botirov Je.H., Kijamitdinova F., Malikov V.M. Himija prirodnyh soedinenij, 1986, no. 1, pp. 111-112. (in Russ.).

6. Vahabov A.A., Hasanova R.H., Nabiev A.N., Juldashev M.P. Farmacevticheskij Vestnik Uzbekistana, 2010, no. 2, pp. 43-46. (in Russ.).

7. Vahabov A.A., Aminov S.D., Hasanova R.H. Doklady Akademii Nauk RUz. 1993, no. 10, pp. 43-45. (in Russ.).

8. Aminov S.D., Vahabov A.A., Hasanova R.H. Doklady Akademii Nauk RUz. 1995, no. 9/10, pp. 43-45. (in Russ.).

9. Hasanova R.H., Vahabov A.A., Aminov S.D. Sozdanie lekarstvennyh resursov lechebno-profilakticheskie sredstva $i$ ih ispol'zovanie v medicinskoj praktike: materialy 1 Respublikanskoj nauchno-proizvodstvennoj konferencii. [Creating a drug resources treatment and prophylactic agents and their use in medical practice: 1 Materials of the Republican scientific-production conference]. Samarkand, 1996, pp. 101-102. (in Russ.).

10. Hasanova R.H., Nabiev A.N., Vahabov A.A. Gastrojenterologija Sankt-Peterburga, 2003, no. 2-3, p. 180. (in Russ.).

11. Gosudarstvennaja Farmakopeja. [State Pharmacopoeia]. Is. 1. Moscow, 1987, 336 p. (in Russ.).

12. Gosudarstvennaja Farmakopeja. [State Pharmacopoeia]. Is. 2. Moscow, 1990, 400 p. (in Russ.).

Received April 15, 2015

Revised February 1, 2016

\footnotetext{
* Corresponding author.
} 